\title{
"Ao povo rio-grandense entrego as minhas provincianas": a literatura no século XIX e a obra de Bernardo Taveira Junior
}

\author{
Mariana Couto Gonçalves
}

Mestranda em História pela Pontifícia Universidade Católica do Rio Grande do Sul. Graduada no curso de Bacharelado em História pela Universidade Federal de Pelotas. Bolsista CNPq. E-mail: marianacoutogon@hotmail.com

Recebido em 04/2012. Aceito para publicação em 12/2012.

Versão online publicada em 01/02/2013 (http://seer.ufrgs.br/paraonde)

\begin{abstract}
Resumo: Durante a segunda metade do século XIX, a Província do Rio Grande do Sul viu despertar em seu solo uma gama de jornais de caráter exclusivamente literário que tinham como objetivo promover os autores locais e regionais. Dessa forma, o artigo visa apresentar os primeiros periódicos literários, destacando a obra do escritor Bernardo Taveira Junior, que publicou inúmeros poemas, romancesfolhetins, crônicas e críticas nestes periódicos e que teve um papel fundamental como colaborador e propagador dos ideais defendidos por estes jornais. Além disso, o artigo propõe analisar a obra "Provincianas" onde Bernardo Taveira Junior apresenta os costumes e tradições do Rio Grande do Sul através de dezoito poemas.

Palavras chaves: Bernardo Taveira Junior. Imprensa. Literatura.
\end{abstract}

\section{Introdução}

0 artigo a seguir tem como objetivo explanar sobre os primórdios da literatura no Rio Grande do Sul, perpassando pela obra do autor provinciano Bernardo Taveira Junior (1836-1892). Além disso, visa apresentar o livro mais notório do autor que se intitula Provincianas, na qual ele apresenta os costumes e tradições do Rio Grande do Sul através de dezoito poemas.

\section{Imprensa no Brasil e no Rio Grande Do Sul:}

A imprensa no Brasil surgiu apenas com a chegada da Família Real, em 1808, instalando a Imprensa Régia, antes disso, era proibido qualquer tipo de impresso no Brasil Colônia. Neste mesmo período, era impresso em Londres o jornal Correio Braziliense, editado por Hipólito José da Costa, cujo objetivo era relatar e discutir os problemas da Colônia ${ }^{1}$.

A introdução da imprensa no Rio Grande do Sul acontece tardiamente com a publicação do jornal o Diário de Porto Alegre, em 1827, dirigido pelo Major Lourenço de Castro Júnior e patrocinado pelo presidente da Província Salvador José Maciel. Carlos Alexandre Baumgarten (1982) destaca que no Rio Grande do Sul, durante um século pratica- mente, não existiu nenhum órgão de imprensa e afirma que isso se deu devido à proibição da metrópole de publicações por parte da colônia, à demora da Província em integrar-se no território nacional, e por fim, aos escassos recursos financeiros que detinha a Província.

Com a proximidade da Revolução Farroupilha, desenvolveram-se diversos jornais e a imprensa nesta época, como aponta Baumgarten (1982), era de caráter partidário, ou seja, o objetivo desta imprensa que se estruturava era difundir as ideias políticas de cada partido. Dessa forma, durante a primeira metade do século XIX, não se observa nenhum jornal exclusivamente de cunho literário na Província. Esta situação irá mudar a partir da publicação do periódico literário o Guaíba, de 1856.

\section{Aliteratura gaúcha no século XIX:}

O surgimento efetivo da literatura no Rio Grande do Sul se dará com a publicação do jornal $O$ Guaíba, em 1856. Este periódico foi editado na cidade de Porto Alegre e circulou de 1856 à 1858. A partir de sua publicação, a Província passou a obter um jornal exclusivamente literário, até então, os jornais eram estritamente de caráter políticopartidário. Todavia, antes de sua publicação, de acordo com Baumgarten (1982), a literatura era 
feita de maneira oral, através da trova.

Segundo Baumgarten (1997) e Guilhermino

Cesar (1971), o jornal O Guaíba agrupou a primeira geração romântica, destacando-se os autores: João Vespúcio de Abreu e Silva, Rita Barém de Melo, Félix da Cunha, Pedro Antônio de Miranda e Carlos Jansen. Além disso, de acordo com Baumgarten (1997, p. 65) "a importância d'O Guaíba radica no fato de ele ter criado um modelo de imprensa literária que teve inúmeros seguidores [...] contribuindo para o desenvolvimento da vida literária da Província". Bernardo Taveira Junior reconheceu o mérito da revista, escrevendo: "Colaborando por diversas penas mais ou menos hábeis, aquele periódico foi a pedra fundamental assentada para o levantamento do edifício de nossas letras" (TAVEIRA JUNIOR apud BAUMGARTEN, 1997, p. 220).

O fechamento das atividades do Guaíba ocorreu devido a dificuldades financeiras. Além disso, ressalta Cesar (1971) que a partir do jornal, os escritores e poetas apareceram em grupos, unidos através de aspirações e ideais por eles compartilhados. Como destaca Baumgarten (1982) o principal mérito d'O Guaíba é ter introduzido na Província a prática da difusão da literatura, sendo assim, incentivando as publicações que vieram posteriormente, como por exemplo: Álbum de Domingo ( Porto Alegre - 1860), O Ipiranga (Porto Alegre - 1863) e O Diógenes (Porto Alegre - 1863).

Após o término d'O Guaíba, em 1867, surge na cidade de Rio Grande a publicação de maior destaque no âmbito da crítica literária no Rio Grande do Sul, o jornal intitulado Arcádia. 0 periódico era de propriedade de Antônio Joaquim Dias ${ }^{2}$, perdurou por quatro anos (1867 à 1870), contando com quatro séries, das quais três foram publicadas em Rio Grande e a última na cidade de Pelotas. Colaboravam com a Arcádia os autores: Bernardo Taveira Junior, Arthur de Lara Ulrich, Apolinário Porto Alegre, entre outros.

Através das páginas da revista Arcádia eram publicadas poesias, crônicas e ensaios de autores rio-grandenses, destacando os estudos biográficos de vultos passados. Bernardo Taveira Junior publicava quase que diariamente suas poesias. Entretanto, destaca-se o ensaio crítico intitulado "Reflexões sobre a literatura Rio Grandense" publicado na $4^{\circ}$ série da Arcádia. Neste texto, escreve:

A Arcádia pois deve ser hoje considerada como um modesto monumento, erguido e conservado pelo amor das letras, que começa por inspirar a nossa juventude. 0 seu nome ocupará um lugar honroso na história de literatura rio-grandense. Ao seu aparecimento, saudado com entusiasmo, despertaram e desenvolveram-se muitos talentos, que, agrupados em torno dela, começaram por formar uma brilhante plêiade de inteligências. (TAVEIRA JUNIOR apud BAUMGARTEN, 1982, p. 98)

Neste ensaio, Bernardo Taveira Junior relata a importância das publicações de viés literário, agora "a mocidade inteligente estuda, aprende, escreve, discute e ilustra finalmente. Era tempo. Nada pode oprimir tanto o homem como as brumas da ignorância" (TAVEIRA JUNIOR apud BAUMGARTEN, 1997, p. 220). Ele alerta os jovens escritores que eles não devem perder a originalidade de seus textos literários, o ser "original" estabelece o verdadeiro caráter da literatura, alertando que os mesmos devem fugir de imitar a literatura de estranhos.

Bernardo Taveira Junior escreveu na Arcádia outro ensaio crítico-literário intitulado Mulher $e$ Mãe. Neste texto, escreve sobre a necessidade de haver uma crítica literária na Província e complementa "letras, sem crítica, jamais poderão constituir uma literatura" (TAVEIRA JUNIOR apud BAUMGARTEN, 1982, p. 101). Além disso, critica o jornalismo que ainda é pouco ilustrado para tratar sobre assuntos literários.

Em 1870, a Arcádia passava por dificuldades financeiras e começou a desenvolver suas atividades como órgão oficial do Grêmio Literário RioGrandense. Efetivamente, foi através das páginas do Guaíba e da Arcádia que os escritores riograndenses difundiram suas poesias e escritos em um veículo de comunicação estritamente literário. Posteriormente, a difusão de suas ideias foi possível através de outra publicação a Revista Mensal do Partenon Literário. Seu surgimento se deu a partir da criação da Sociedade Partenon Literário, fundada em 1868 na cidade de Porto Alegre, por iniciativa de um grupo de jovens.

De fato, a Sociedade do Partenon Literário ${ }^{3}$, segundo Baumgarten (1997, p. 70) foi "o mais importante grêmio cultural sul-rio-grandense da segunda metade do século XIX". O principal objetivo do Partenon era a difusão da literatura sulina na Província. Contava com os escritores: Bernardo Taveira Junior, Apolinário Porto Alegre, Aquilles Porto Alegre, Lobo da Costa, Múcio Teixeira, Caldre e Fião, José Bernardino dos Santos, entre outros. Conforme aponta Regina Zilberman (1992, p. 13) “o início efetivo da literatura no Rio Grande do Sul

${ }^{2}$ Sobre Antônio Joaquim Dias ver (CALDERAN, 2002).

${ }^{3}$ Sobre a Sociedade do Partenon Literário ver (SILVEIRA, 2008); ( ZILBERMAN, 1992). 
coincide com o trabalho dos escritores que tomaram parte nessa agremiação".

Sobre os ideais que a sociedade difundia, Cássia Daiane Macedo da Silveira (2008) destaca o abolicionismo, republicanismo e a emancipação feminina. Esses ideais eram expostos e apresentados ao público através da Revista Mensal. A revista manteve-se regularmente por dez anos (18691879), desempenhando um papel significativo em Porto Alegre e no interior da Província. Organizava saraus literários, reuniões onde eram lidas peças teatrais, ensaios, poemas e preocupava-se em propiciar o acesso à leitura e, para isso, criou a sua própria biblioteca. Sobre os objetivos da Sociedade, afirma Cesar (1971) que ela agremiou prosadores, poetas e homens de teatro.

A Sociedade do Partenon Literário foi extremamente destacada durante a segunda metade do século XIX. Como afirma Cesar (1971, p. 173) “até aqui, antes do aparecimento do Partenon, fora desordenada a atividade literária". Agora, completa ele "abre-se [...] o ciclo da literatura regionalista, dita gauchesca". Dessa forma, temos a publicação da obra Provincianas de Bernardo Taveira Junior que apresenta os costumes e tradições do gaúcho.

\section{"[...] trato de um professor distinto, de um escri- tor de reconhecido mérito ${ }^{4}[. .]$.}

Bernardo Taveira Junior nasceu na cidade de Rio Grande em 1836, filho do português Bernardo Taveira e da brasileira Gertrudes Maria de Melo. Desde cedo, dedicou-se à causa das letras. Primeiramente, foi estudar direito na cidade de São Paulo. Entretanto, completou apenas o curso de preparatórios. Devido a escassos recursos financeiros e a sua saúde debilitada, ele regressa, por conselho médico, ao Rio Grande do Sul. Sua permanência no interior da Província serviu de subsidio para escrever a sua mais famosa obra literária intitulada as Provincianas.

Após regressar à Província do Rio Grande do Sul, Bernardo Taveira Junior começou a lecionar nos principais colégios de ensino primário e secundário da cidade de Pelotas. Ensinava aos seus alunos latim, história, filosofia, inglês, português, francês, alemão, retórica, entre outros. Baseado no corpus documen$\mathrm{tal}^{5}$ analisado, foi possível constatar a presença de Bernardo Taveira Junior em quatro instituições de ensino feminino: Collegio de Mme. Jeanneret, Collegio de Instrução Elementar, Collegio Acacia e o Collegio Perseverança. Além destes, promoveu em sua residência quatro cursos de preparatórios, destacandose também a sua atuação no curso particular oferecido na residência de José Vieira da Cunha. Por fim, lecionou em nove instituições de ensino dedicadas ao público masculino: Collegio Francez, Lyceu Municipal, Collegio Franco Rio-Grandense, Collegio Pelotense, Collegio Osorio, Collegio Rio Grandense, Collegio Curso Racional, Collegio Sul-Americano e o Collegio Atheneu Pelotense.

Além da carreira de professor, Bernardo encontrava-se associado à imprensa. Nas colunas dos jornais, publicava crônicas, folhetins e poemas. Uma bandeira defendida por ele era a abolição dos escravos. Sobre o tema, escreveu poemas e crônicas principalmente durante a segunda metade do século XIX. Dessa forma, ia de encontro com à sociedade pelotense na época. A cidade de Pelotas no século XIX, conhecida como a "Princesa do Sul", desenvolvia-se economicamente graças as charqueadas implantadas por José Pinto Martins. De acordo com Mario Osório Magalhães (1993) o auge econômico de Pelotas deu-se de 1860 à 1890 . Este auge fica evidente devido a pujança econômica da cidade, proporcionando uma sociedade aristocrática e escravocrata que tinha na Europa a sua inspiração. Para Bernardo, o escravo deveria ser livre, ou seja, ele ia de encontro à sociedade de sua época. Sobre isso, Baumgarten afirma:

\begin{abstract}
Bernardo Taveira Junior destacou-se na vida da Província pela luta que sempre manteve contra a escravatura. Vivendo em Pelotas, centro de grande concentração de escravos, devido às charqueadas, o autor possuía uma vivência bastante grande do problema da escravatura. Por sua posição contrária ao regime escravagista, muitas foram as ameaças que sofreu, embora nunca tenha cessado de, através de seus poemas, lutar pela abolição. (BAUMGARTEN, 1982, p. 57)
\end{abstract}

No decorrer de sua vida, Taveira Junior publicou algumas obras literárias. A primeira editada na tipografia da Arcádia, datada de 1869, intitula-se Poesias Americanas. Este livro reúne dez poesias, cujos títulos são: Visões; Cunhambebe; $O$ canto das amazonas; Ayuára; O membira; O Gua-

${ }^{4}$ Citação extraída da notícia publicada no jornal Ventarola (Pelotas/RS) de 25/09/1887.

${ }^{5} \mathrm{O}$ corpus documental são os jornais pelotenses do século XIX. São eles: Correio Mercantil, A Discussão, Diário de Pelotas, Jornal do Comércio e A Pátria. O recorte da pesquisa compreende o ano de 1875 como ano inicial, pois é o exemplar mais antigo encontrado na Bibliotheca Pública Pelotense e o ano de 1892 como ano final, pois é o ano da morte de Bernardo Taveira Junior. 
rany; O aimoré; O caiapó; Jacy; Sete de setembro. A obra foi inspirada no indianismo de Gonçalves Dias, evidenciado na grande quantidade de palavras indígenas. Outra peculiaridade marcante é a atribuição do índio como símbolo nacional.

Em 1875, Bernardo Taveira Junior publica seu segundo livro intitulado Poesias Alemãs. O livro foi impresso pela tipografia Deutsche Zeitung e conta com o prefácio de Carlos Von Koseritz. Neste livro, ele apresenta uma série de traduções de autores renomados como Goethe, Heine, Geibel, Lenau, entre outros. Koseritz afirma que ler o original e ler a tradução de Bernardo é praticamente a mesma coisa e ainda afirma no Jornal do Comércio (02/05/1875):

Estou certo que todos os homens de letras, todos os entendedores de boa poesia, confessarão comigo que Bernardo Taveira pode dizer: Também eu sou poeta! Com o mesmo direito com que Correggio exclamava ante uma tela de Raphael: Anch'io sono pintor! (VON KOSERITZ, 1875, p. 02)

O livro Poesias Alemãs recebeu uma segunda edição 1884 contando com aproximadamente 313 páginas. De acordo com Pedro Theobald (2008, p. 47) este livro "é certamente uma das mais antigas antologias de poesia alemã in existense no Brasil". Entretanto, a obra que mais gerou frutos e atingiu notoriedade de Bernardo Taveira Junior foram as Provincianas.

Além da publicação destas três obras, Bernardo Taveira Junior publicou três poemetos. 0 primeiro intitulado Primus Inter Pares, dedicado à memória de Alexandre Herculano, o segundo intitulado Ave, poeta! (1885) dedicado a memória de Victor Hugo e o último poemeto intitulado $O$ enterro (1888) referente à libertação dos escravos.

Bernardo Taveira Junior morreu em 19 de setembro de 1892, na cidade de Pelotas, diagnosticado de diabetes. De acordo com o jornal Correio Mercantil (22/09/1892) ele morreu paupérrimo. Após a sua morte, recebeu algumas homenagens póstumas, como por exemplo, as homenagens através do centenário da Sociedade do Partenon Literário.

\section{"Ao povo rio-grandense entrego as minhas pro- vincianas"}

O livro Provincianas foi publicado em 1886, mas Bernardo Taveira Junior afirma que a obra estava pronta em 1873. As poesias contempladas no livro se intitulam: Rio Grande do Sul; Os nossos campos; $O$ vaqueano; $O$ canto do gaúcho; $O$ rancho; $O$ tropeiro; $O$ laçado; Carreiras; $O$ boleador; A marcação; $O$ domador; $O$ rodeio; $O$ gateador de marrecas; Declaração; Tio e sobrinho; $O$ casamento; $O$ camponês; $O$ cavalo moribundo. No prefácio, afirma:

\begin{abstract}
Não tenho notícia, até ao presente, de que haja algum patrício meu, literato, poetizado sobre assuntos puramente com respeito ao nosso campeiro, e aos seus hábitos, costumes e tradições. [...] Cumpre-me advertir que a poesia a que me refiro agora não é essa que, de quando em quando, por ai aparece em estilo chulo, e sem mérito algum literário. [...] Aos campeiros do sul entrego a apreciação da fidelidade do que sobre eles escrevi; quanto à parte literária, essa, reservo-o para os entendidos. [...] Uma coisa única direi a meu favor: é que poetizei sobre coisas que me passaram pelos olhos, e das quais tenho pleno conhecimento. [...] Ninguém escreva sobre o que não conhece ou viu, ou ainda confiado em informações destituídas de todas as verossimilhanças. (TAVEIRA JUNIOR, 1886, grifo nosso)
\end{abstract}

Bernardo Taveira Junior utiliza de seu prefácio para enfatizar que foi o primeiro escritor letrado a escrever sobre o gaúcho. Para ressaltar isso, afirma que o livro encontrava-se pronto desde 1873. Apesar da afirmativa dele, outros trabalhos sobre o gaúcho foram publicados e a primazia de Bernardo pode cair por terra. Em 1870, José de Alencar publica o romance 0 Gaúcho. Em 1872, é publicado na Argentina o livro O gaúcho Martin Fierro de José Hernández. Além disso, a afirmativa de Taveira Junior também é criticada por seu colega de Partenon Múcio Teixeira. De acordo com Múcio, em 1873, ele e Apolinário Porto Alegre já haviam escrito sobre o pampa gaúcho. Sobre isso, escreve Baumgarten:

Em 1869, Taveira Junior já havia publicado na Arcádia um artigo crítico onde defendia a necessidade dos autores utilizarem os costumes, as lendas e as tradições do Estado em suas obras, o queleva a crer que o autor tenha se dedicado ao cultivo destes temas bem antes de 1886. (BAUMGARTEN,1982, p. 61)

A partir da publicação da obra, os jornais

${ }^{7}$ Apresentado por Bernardo Taveira Junior no "Convêm ler", prefácio do livro Provincianas. 
pelotenses noticiaram sobre o mesmo. 0 Correio Mercantil (27/08/1886, p. 03) afirma: "É este o título de uma esplêndida coleção de poesias do assaz conhecido e laureado poeta pelotense Bernardo Taveira Junior. [...] notáveis pela beleza da forma, como pela expressão da verdade". Observando apenas o título das poesias já evidencia-se a preocupação do autor em enfatizar o gaúcho e seus costumes, como é o caso dos poemas: o vaqueano, $o$ tropeiro, o laçador, o domador, entre outros. Autores contemporâneos analisaram e criticaram a obra em seus livros, destacando-se: Donaldo Schüler, Carlos Alexandre Baumgarten, Regina Zilberman, Guilhermino Cesar, João Pinto da Silva.

Schüller, que analisa a obra e em seu livro $A$ poesia no Rio Grande do Sul, elucida que Bernardo Taveira Junior apresenta a "sua gente" no livro, porém afirma que o discurso das Provincianas é o mesmo do livro Poesias Americanas. Em contraponto, Cesar (1994) compreende sobre outro aspecto as Provincianas:

Com toda a sua falta de ritmo, a sua aspereza melódica, assinalam a transição do arcadismo para o regionalismo de feição romântica, no Rio Grande, como uma vivacidade temática exemplar [...] Nenhum dos grandes temas da gauchesca foi desprezado por Taveira Junior. Descobriu-os com enlevo, sabendo que estava chegando em primeiro lugar. Valorizou quanto pode o homem gaúcho, suas técnicas de trabalho, suas diversões, sua fala, sua natureza que lhe é familiar. (CESAR, 1994,p. 24)

Guilhermino Cesar (1971) apresenta em seu livro História da Literatura do Rio Grande do Sul algumas particularidades da obra de Bernardo Taveira Junior. A primeira delas é o surgimento de uma novidade por parte do autor. Antes, os leitores estavam acostumados com outro tipo de leitura evidenciados neste fragmento:

O leitor da época se acostumara a outro tipo de poesia; o lirismo casimiriano havia já substituído o indianismo e atenuara de muito o prurido americanista. Com os últimos românticos, um sem-número de autores tendiam no plano da ficção para a vida campestre, para o homem do interior, numa palavra-encorpava-se o regionalismo para empreender uma dura batalha, que ainda continua. Apolinário Porto Alegre [...] publicara na sua revista 0 vaqueano. Mas, afora este e 0 crioulodo-pastoreio, do mesmo autor, a Divina
Pastora e 0 Corsário, de Caldre e Fião, e Os Farrapos, de Oliveira Belo, todos em prosa, nenhum outro livro tão deliberadamente gauchesco havia pintado com maior pachorra as labutas do pastoreio e os hábitos do peão da estância. Taveira Junior surge, pois, como uma novidade. (CESAR, 1971, p. 193)

Cesar afirma que era necessário preparar o leitor para receber esta nova poesia e que Bernardo facilitou a tarefa ao inserir o vocabulário crioulo nas poesias. Afirma que ele foi o primeiro a publicar um livro homogêneo. Ainda critica a estética da poesia, colocando-a como inferior. 0 crítico João Pinto da Silva (1930) autor do livro História literária do Rio Grande do Sul destaca que, para ele, Bernardo tem mais mérito como tradutor do que como poeta. Sobre o livro, Baumgarten (1982) afirma que a poesia mais representativa intitula-se Rio Grande do Sul:

\section{" [...] És a terra fecunda em que nasceram Bento Gonçalves, Canabarro e Neto- As águias a quem sempre alvoreceram Belas auroras de um porvir dileto!... \\ Oh! Já muito mais longe esteve a esperança De remir-nos de velha monarquia! Aqui de trinta e cinco a ideia avança $E$ de hora em hora engendra o grande dia.}

(Bernardo Taveira Junior - Rio Grande do Sul)

Neste poema, Baumgarten (1982) afirma que Bernardo Taveira Junior exalta a figura do gaúcho, de seus feitos na Revolução Farroupilha e, de sua consciência de liberdade. Além das tradições rio grandenses, os temas mais abordados pelo autor são a natureza, a morte, a juventude, o amor, o índio o homem da terra.

Os críticos ao analisarem as Provincianas apontam Bernardo Taveira Junior como um dos autores que implantaram o ideário romântico no Rio Grande do Sul, mesmo o criticando. Entretanto, concordam que sua contribuição foi de suma importância para a literatura do século XIX na Província do Rio Grande do Sul. Como aponta Baumgarten (1982, p. 62) "A sua obra poética e o conjunto de textos críticos que produziu lhe asseguraram um lugar de destaque na literatura da segunda metade do século XIX". Além disso, ele tem um lugar de destaque na cidade de Pelotas devido a sua atuação como professor e como cultor das letras. Ao escrever sobre o que acreditava, Bernardo Taveira Junior contribuiu para que a sociedade refletisse sobre o que ele defendia e acreditava. 


\section{Referências}

BAUMGARTEN, Carlos Alexandre. Literatura e crítica na imprensa do Rio Grande do Sul 1868 a 1880. Porto Alegre: Escola Superior São Lourenço de Brindes, 1982.

A crítica literária no Rio Gran-

de do Sul do romantismo ao modernismo. Porto Alegre: IEL: 1997

CESAR, Guilhermino. História da literatura do Rio Grande do Sul. Porto Alegre: Ed. Globo, 1971.

Notícia do Rio Grande: literatura. Porto Alegre: Ed. UFRGS, 1994.

CALDERAN, Ana Paula. Antônio Joaquim Dias: uma figura polêmica. Pelotas: UFPel, 2002 (trabalho de conclusão de curso)

GONÇALVES, Mariana Couto. Bernardo Taveira Junior: a luta abolicionista através da imprensa pelotense. Anais eletrônicos do I Congresso Internacional de História Regional. Volume II. Passo Fundo: 2011.p. 1831-1841

LUCA, Tania Regina de; MARTINS, Ana Luiza. História da imprensa no Brasil. São Paulo: Contexto, 2008.

MAGALHÃES, Mario Osório. Opulência e cultura na província de São Pedro do RS: um estudo sobre a história de Pelotas (1860-1890). Pelotas: Ed.UFPEL, 1993.

SCHÜLER, Donaldo. A poesia no Rio Grande do Sul. Porto Alegre: Mercado Aberto, 1987. SILVA, João Pinto da. História literária do Rio Grande do Sul. Porto Alegre: Livraria do globo, 1930.

SILVEIRA, Cássia Daiane Macedo da. Dois pra lá, dois pra cá: 0 Parthenon Litterario e as trocas entre literatura e política na Porto Alegre do século XIX. Porto Alegre: UFRGS, 2008. (Dissertação de Mestrado)

TAVEIRA JUNIOR, Bernardo. Provincianas. Porto Alegre: Movimento, 1986.

THEOBALD, Pedro. Formas e tendências da historiografia literária: 0 caso da literatura alemã no Brasil. Porto Alegre: UFRGS, 2008. (tese de doutorado)

ZILBERMAN, Regina. A literatura no Rio Grande do Sul. Porto Alegre: Mercado aberto, 1992.

\footnotetext{
Abstract: In the second half of the XIX century, the province of Rio Grande do Sul seen wake in your soil a number of newspapers exclusively literary nature that was intended to promote local and regional authors. Therefore, the article presents the first (and singular) literary journals, highlighting work of Bernardo Junior Taveira writer who published numerous poems, novels, pamphlets, essays and reviews in magazines and they played an important role as a developer and propagator of the ideals espoused by those newspapers. Furthermore, the article proposes to analyze the work "Provincianas", where Bernardo Junior Taveira presents the customs and traditions of Rio Grande do Sul state through 18 poems.

Keywords: Bernardo Taveira Junior. Press. Literature.
} 